\title{
Testing the Expectations Hypothesis: Some New Evidence for Japan
}

\author{
Daniel L. Thornton
}

\section{INTRODUCTION}

$\mathbf{S}$ pending decisions, especially investment decisions, are largely determined by longterm interest rates, while the actions of the monetary authority have a direct effect on interest rates only at the very short end of the yield curve. An important question in monetary economics and finance is, How do the actions of the monetary authority get translated along the entire yield curve? In countries where a wide variety of bonds with different maturities are traded, policy actions are thought to be translated from the short end to the long end of the term structure in accordance with the expectations hypothesis (EH), which asserts that the long-term rate is equal to market participants' expectation of the short-term rate over the holding period of the long-term asset plus a constant risk premium.

Until the mid-1980s, the Japanese bond market was relatively small, illiquid, and tightly regulated. Japan's capital markets were segmented by government regulations, not the public's preferences.

Arbitrage opportunities across maturities were limited. Few thought that the EH applied to Japan. Consequently, there was no reason to test the EH for Japan. Monetary policy was thought to affect lending through quantity constraints and not through interest rates.

The Japanese began to deregulate their bond market in the 1970s. The structural changes in the Japanese financial markets have generated considerable interest in testing the $\mathrm{EH}$ using Japanese data (e.g., Campbell and Hamao, 1993; Singleton, 1990; Shirakawa, 1987; and Shikano, 1985). This paper is an extension of this research agenda, but differs from the previous literature in two respects. First, this paper investigates the EH by estimating a bivariate vector autoregression (VAR) for the longterm and short-term interest rates and testing the restrictions implied by the $\mathrm{EH}$. This test was first suggested by Campbell and Shiller (1987); however, the procedure used here was developed by Bekaert and Hodrick (2001). ${ }^{1}$

Second, this paper deals directly with the issue of stationarity. While stationarity is frequently considered in testing the $\mathrm{EH}$, its implications for the $\mathrm{EH}$ are seldom discussed. This paper attempts to fill this void. As a matter of theory, many economists and financial specialists appear to believe that interest rates are stationary. If they are not, the role played by the EH in monetary policy may be diminished.

As a practical matter, interest rates tend to exhibit considerable persistence. Indeed, the null hypothesis of nonstationarity is frequently not rejected even in relatively large, finite samples. This is particularly important for Japanese interest rates because they exhibit considerable persistence at the monthly frequency. It is well known, however, that tests of unit roots may have low power. Moreover, many financial market economists argue that interest rates are stationary on theoretical grounds. Given the differences of opinion about whether interest rates are stationary in general, the VAR test is applied under the assumption that interest rates are either stationary or nonstationary. The issue of stationarity is important only if the conclusions concerning the EH differ markedly depending on the assumption made.

\footnotetext{
1 Several of the tests of the EH that are frequently used have low power and, more importantly, tend to generate results that can give a misleading impression of the strength or weakness of the EH. For a more detailed discussion of this problem, see Thornton (2002 and 2003a) and Kool and Thornton (2003).
}

Daniel L. Thornton is a vice president and economic advisor at the Federal Reserve Bank of St. Louis. This paper was prepared while the author was a visiting scholar at the Institute for Monetary and Economic Studies and was previously published (Institute for Monetary and Economic Studies, Bank of Japan, Monetary and Economic Studies, May 2004, 22(2), pp. 45-69); it is reprinted here with permission. The views expressed are the author's and may not reflect the views of the Bank of Japan, the Federal Reserve Bank of St. Louis, or the Board of Governors of the Federal Reserve System. The author thanks Rob Dittmar, Hiroshi Fujiki, Marco Lippi, Takatoshi Ito, Shigenori Shiratsuka, Yi Wen, and an anonymous referee for helpful comments. Molly Dunn-Castelazo, John Zhu, and Kiyoshi Watanabe provided valuable research assistance.

Federal Reserve Bank of St. Louis Review, September/October 2004, 86(5), pp. 21-39.

(1) 2004, The Federal Reserve Bank of St. Louis. 
Japanese short-term interest rates, which began a rapid descent in late 1990, have hovered about their theoretical zero bound since mid- to late 1998. This feature of Japanese interest rates makes testing the EH after 1998 particularly difficult.

Section II discusses the evolution of Japanese financial markets during the postwar period and reviews the literature on tests of the EH in Japan in the postwar period. The data and some initial data analysis are presented in Section III. Section IV discusses nonstationarity and its implications for the EH. Some preliminary tests of the $\mathrm{EH}$, which arise from the discussion in Section IV, are presented in Section V. In Section VI, the VAR test is applied to Japanese data under both assumptions - that interest rates are stationary or nonstationary, but cointegrated. The results of these tests are presented and discussed. The implications for rejecting the $\mathrm{EH}$ are presented in Section VII, and the conclusions are presented in Section VIII.

\section{JAPANESE FINANCIAL MARKETS AND THE EH}

\section{A. Evolution of Japanese Financial Markets}

The Japanese financial markets were highly regulated during the early postwar period. There was virtually no issuance of government debt during the first 15 years of the postwar period. Hence, there was little need for a government debt market. When, in the mid-1960s, the government needed to borrow to finance infrastructure, regulations were introduced that significantly limited the development of a secondary market in government debt. Specifically, banks were not permitted to resell government debt in the secondary market. Instead, there was an implicit guarantee that the Bank of Japan would purchase the government debt after a holding period of 1 year. In addition, securities companies were under administrative guidelines to maintain yields in the secondary market as close as possible to primary market yields. These restrictions significantly impeded the development of a secondary government debt market. ${ }^{2}$

Japanese corporations relied heavily on internal funds and loans from private financial institutions to finance investment. Equity and debt accounted for less than 5 percent of industrial funds prior to 1975 (Hodder, 1991).

2 For additional details on these restrictions, see Takagi (1988).
The effect of the oil-price shock in the early 1970s facilitated the development of the gensaki market (the market for bond repurchase agreements) and the secondary market in government debt. A decrease in corporate investment following the oilprice shock led to an improvement in short-term corporate cash flows. This facilitated the expansion of the gensaki market, as firms sought alternatives to regulated bank deposits. The development of the gensaki market was enhanced further when the government formally recognized it and instituted prudential guidelines in 1976 (Takagi, 1988).

At the same time, deficit spending increased. The increased holding of government debt by banks prompted the Bank of Japan to suspend its commitment to repurchase government debt held for 1 year, which resulted in an erosion of bank liquidity. To shore up bank liquidity and to avoid debt monetization by the Bank of Japan, in April 1977 banks were permitted to sell government securities in the secondary market after a 1-year holding period. In addition, the requirement that secondary yields remain as close as possible to primary yields was lifted. Restrictions on banks' participation in the secondary market were eased further over time and eliminated in June 1985.

Simultaneous with these developments, the Japanese made a number of successive regulatory changes to liberalize cross-border capital flows. These and other steps toward financial deregulation resulted in deeper and more liquid financial markets, reduced transactions costs, and increased the substitution between assets with different characteristics and between assets with similar characteristics but different maturities (e.g., Singleton, 1990; Leung, Sanders, and Unal, 1991; and Takagi, 1988).

\section{B. The EH in Japan}

In financial markets where there is little possibility for arbitrage between assets with similar characteristics but of different maturities, there is little reason to think that the EH will hold. It is not surprising, then, that there was virtually no statistical testing of the EH using Japanese data prior to the mid-1980s. Financial market deregulation changed this. Since the 1980s, a number of researchers have tested the EH in Japan, where, as elsewhere, it is generally rejected.

Contrary to expectations, evidence supporting the EH appears to be strongest during periods when regulatory constraints effectively segmented longterm and short-term financial markets and weakest 


\section{Figure 1}

3-Month Gensaki Rate and 114-Month Treasury Yield

(March 1981-January 2003)

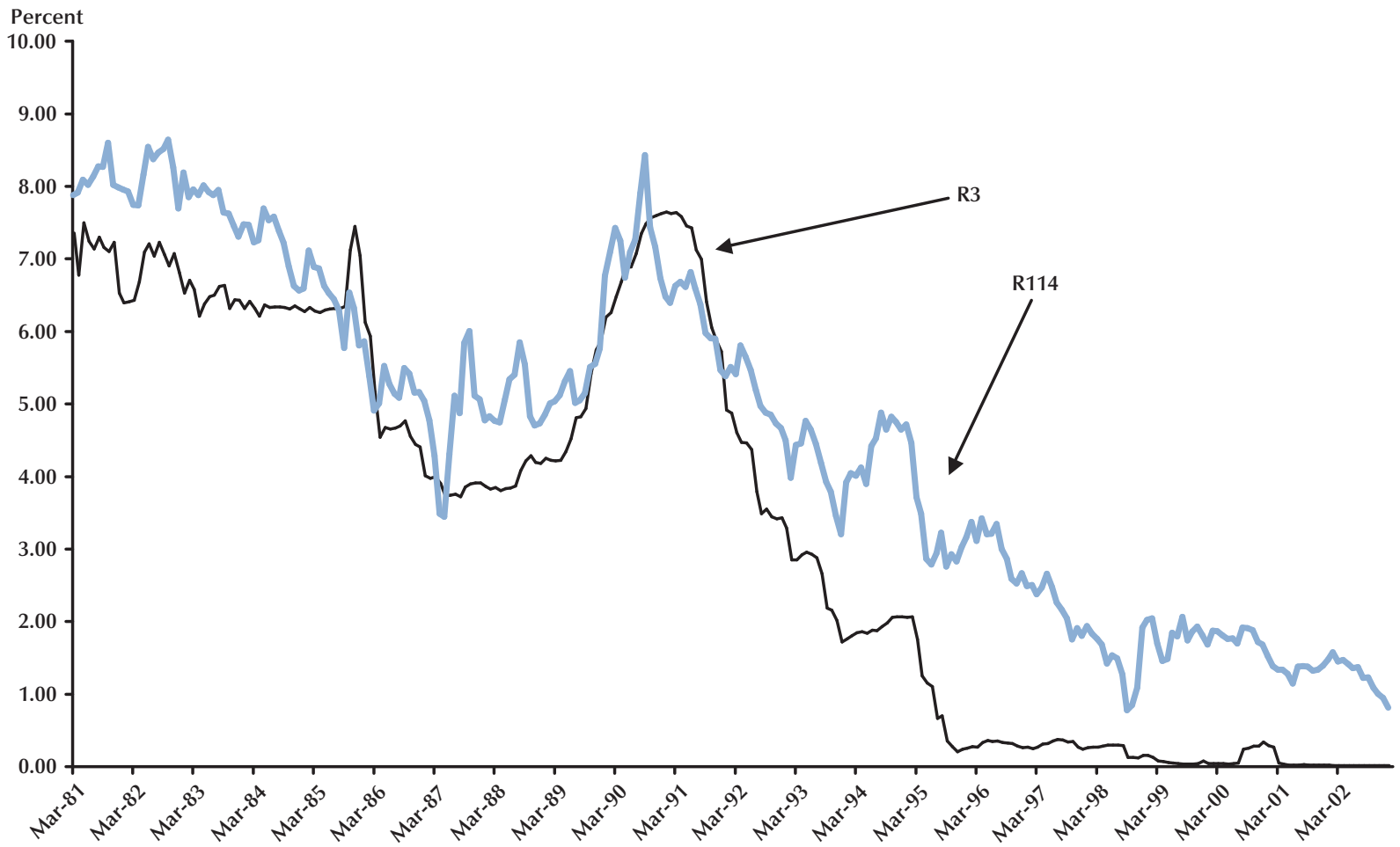

when deregulation provided greater arbitrage opportunities. Shikano (1985) analyzes data from April 1977 to June 1984 . He finds that the $\mathrm{EH}$ was not rejected for the entire period, but was rejected for the period October 1981 to June 1984. Similarly, Campbell and Hamao (1993) test the EH for the periods November 1980 through July 1985 and August 1985 through August 1990. While the EH is rejected for both periods, the qualitative evidence against the $\mathrm{EH}$ is stronger during the latter period. Similarly, Shirakawa (1987) finds that the EH fares worse for the period April 1981 through June 1986 compared with the period April 1977 through June 1986.

\section{JAPANESE INTEREST RATES}

\section{A. Data}

The data are end-of-month observations for the period March 1981 to January 2003. The rates include the 3-month gensaki rate and rates on Japanese government bonds (JGBs) with maturities of 0 to 1 year, 1 to 2 years, 2 to 3 years, up to 9 to 10 years. These data appear to be similar to those used by Campbell and Hamao (1993), which covered the period November 1980 to August 1990. Following Campbell and Hamao's taxonomy, the Treasury rates are designated as 6-, 18-, 30-, 42-, 60-, 78-, 90-, 102-, and 114-month rates, respectively. The gensaki rate was obtained from the Japan Securities Dealers Association, and the Treasury rates were obtained from the Bloomberg database. In cases where Treasury rates were missing, the Bloomberg data were supplemented with data compiled by the Bond Market Underwriter's Association. ${ }^{3}$

Figure 1 shows the 3-month gensaki rate and 114-month JGB yield over the March 1981-January 2003 period. Japanese rates declined generally until the late 1980s, rose until early 1990, and have since generally declined. Since the early 1990s, the gensaki

3 I would like to thank Kiyoshi Watanabe for compiling these data. There was one missing observation for the 6-month rate that occurred on July 1992. The July observation was interpolated from the June and August 6-month rates. 
rate has fallen much more rapidly than long-term rates. This is especially true during the first half of the 1990s, when the spread between the 114-month and 3-month rates increased dramatically. Moreover, since January 1992 the spread between the 114month and 3-month rates has averaged nearly 175 basis points compared with about 60 basis points for the period up to January 1992.

\section{B. The EH and the Zero Bound}

The deterioration in the Japanese economy's performance in the early 1990s and the more recent deflation have greatly affected interest rates. Because of deflation, the gensaki rate has been at or near the zero nominal interest rate bound since late 1998. The zero bound has implications for testing the EH. Because market participants may still form expectations of the future behavior of the short-term interest rate (e.g., Okina and Shiratsuka, 2003), a zero interest rate policy may impact longer-term rates through the EH. What matters for the effectiveness of the $\mathrm{EH}$ is what Fujiki and Shiratsuka (2002) call the "policy duration effect"-i.e., how long the market anticipates that the monetary authority will maintain the current target rate - not whether monetary policy actions are anticipated (e.g., Thornton, 2003b). It is nevertheless the case that, when the short-term rate is at the zero bound, the spread between the longterm and short-term rate need not provide information about the direction of changes in the short-term real rate.

\section{Persistence of Japanese Interest Rates}

Like U.S. interest rates, Japanese interest rates exhibit considerable persistence. The results of augmented Dickey-Fuller tests (Dickey and Fuller, 1979) are reported in Table 1. Because the qualitative conclusions were sensitive to the choice of lag length, the lag lengths were chosen by the Schwarz criterion and are denoted in parentheses below the Dickey-Fuller test statistic. The results indicate that the null hypothesis of a unit root is not rejected even at the 10 percent significance level for any of the rates.

The conclusions are robust over the sample period. This is illustrated in Figure 2, which shows the results from applying the augmented DickeyFuller test to a rolling sample of 78 monthly observations for the 3-, 66-, and 114-month rates. The results for the other Treasury rates are similar to those shown in Figure 2. In general, the degree of persistence increases with the maturity of the rate. Except for some relatively short periods, and primarily for the gensaki and other shorter-term rates, the null hypothesis of a unit root is not rejected. It is well known that the augmented Dickey-Fuller test is sensitive to shifts or breaks in the time-series process. Hence, the conclusion that rates have a unit root is not too surprising given the marked decline in the level of rates in mid-1996. However, the unit root hypothesis is also not rejected for any of the rates for the seemingly more stable period from March 1981 to October 1990.

\section{Volume of Trade}

It is important to note that, like the U.S. market for Treasury securities, trading in Japanese Treasury securities is focused on maturities at or near that of the benchmark issue. When the trading volume on a particular issue of Treasury debt with approximately 10 years of term remaining becomes large enough, it might be designated by the market to be the "benchmark" issue. An issue remains the benchmark issue until another issue receives this designation. There have been a number of benchmark issues since August 1983. Higo (2000) reports that the average maturity of an issue when it was first designated the benchmark issue is just under 10 years. Trading volume in the Japanese Treasury market tends to be focused on the benchmark issue, maturities close to that of the benchmark issue, and, to a much lesser extent, previous benchmark issues regardless of their remaining maturity (Higo, 2000). The market for other issues is relatively thin.

If the markets are thin, there may be day-to-day or month-to-month variation in the rate that is due solely to random variation owing to the thinness of the market. One way to investigate whether the thinness of the markets for shorter-maturity assets might impact our results is to determine whether the variance of the rates declines as the maturity approaches that of the benchmark issue. This is done here by calculating the ratio of the variance of the rate at each maturity to the variance of the 3 -month rate. If the thinness of the market is an important factor, one might expect to see a marked drop in the variance ratio as the maturity approaches 10 years.

Because of uncertainty as to whether interest rates are stationary or unit root processes, the variance ratios are calculated for the levels and first differences of the rates. The variance ratios for levels and first differences are shown in Figures 3 and 4, 


\section{Table 1}

Augmented Dickey-Fuller Tests for Japanese Treasury Rates

\begin{tabular}{|c|c|c|c|c|c|c|c|c|c|c|c|}
\hline & R3 & R6 & R18 & R30 & R42 & R54 & R66 & R78 & $\mathbf{R 9 0}$ & R102 & R114 \\
\hline \multicolumn{12}{|c|}{ March 1981-January 2003} \\
\hline DF & $\begin{array}{c}-1.13 \\
(3)\end{array}$ & $\begin{array}{c}-1.00 \\
(0)\end{array}$ & $\begin{array}{c}-1.51 \\
(2)\end{array}$ & $\begin{array}{c}-1.14 \\
(0)\end{array}$ & $\begin{array}{c}-1.09 \\
(0)\end{array}$ & $\begin{array}{c}-0.96 \\
(0)\end{array}$ & $\begin{array}{c}-0.88 \\
(0)\end{array}$ & $\begin{array}{c}-1.32 \\
(1)\end{array}$ & $\begin{array}{c}-1.28 \\
(0)\end{array}$ & $\begin{array}{c}-0.97 \\
(0)\end{array}$ & $\begin{array}{c}-0.86 \\
(0)\end{array}$ \\
\hline \multicolumn{12}{|c|}{ March 1981-October 1990} \\
\hline DF & $\begin{array}{c}-1.28 \\
(4)\end{array}$ & $\begin{array}{c}-1.23 \\
(0)\end{array}$ & $\begin{array}{c}-1.33 \\
(0)\end{array}$ & $\begin{array}{c}-1.38 \\
(0)\end{array}$ & $\begin{array}{c}-1.31 \\
(0)\end{array}$ & $\begin{array}{c}-1.22 \\
(0)\end{array}$ & $\begin{array}{c}-1.11 \\
(0)\end{array}$ & $\begin{array}{c}-1.30 \\
(0)\end{array}$ & $\begin{array}{c}-1.56 \\
(0)\end{array}$ & $\begin{array}{c}-1.44 \\
(0)\end{array}$ & $\begin{array}{c}-1.50 \\
(0)\end{array}$ \\
\hline
\end{tabular}

NOTE: Parentheses indicate lag length.

\section{Figure 2}

\section{Rolling Augmented Dickey-Fuller Test for Selected Rates}

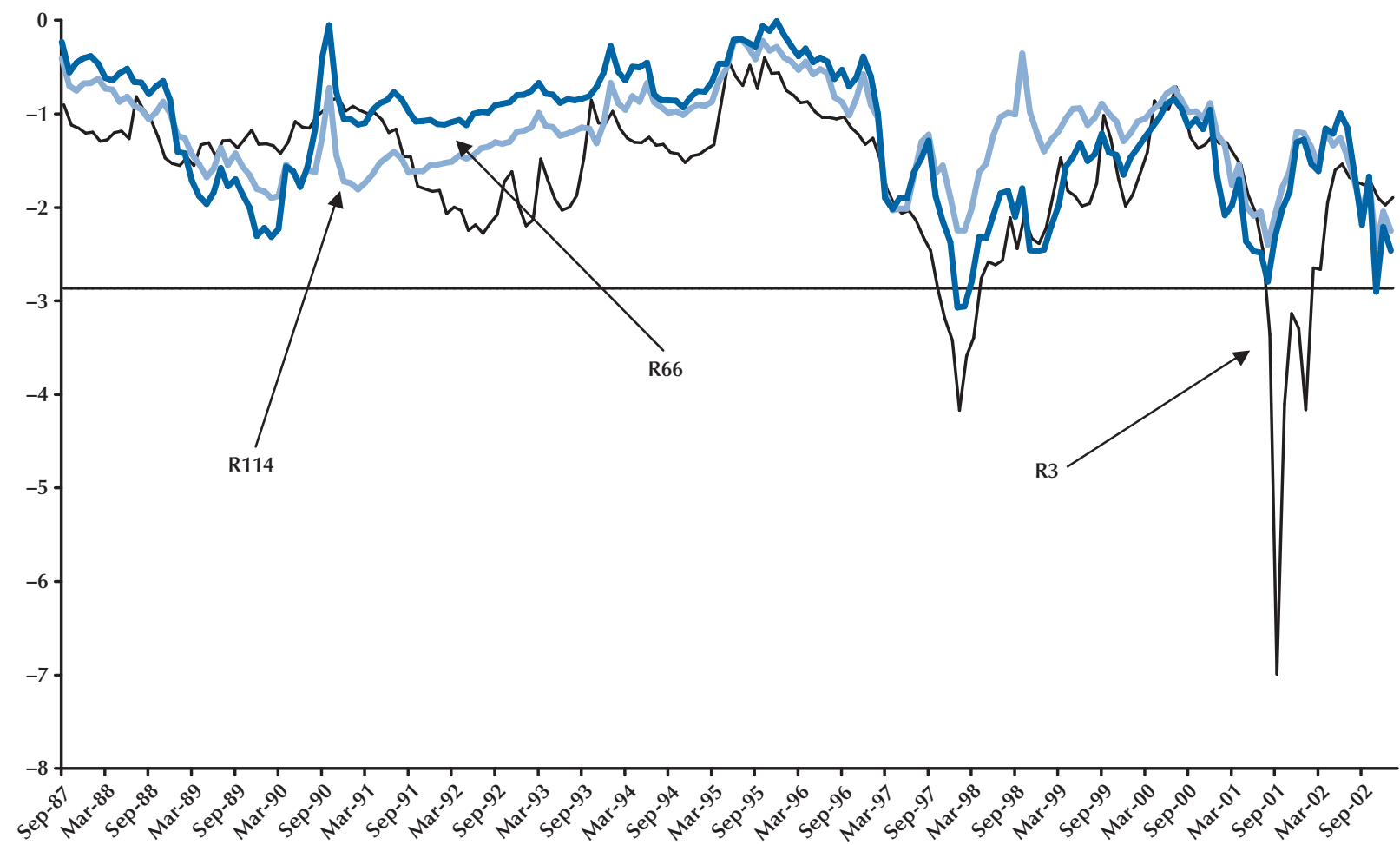

respectively, for selected periods. Figure 3 suggests the possibility of a thin-market effect for the period March 1981-October 1990, when the variance ratio increases to a maturity of 78 months and then declines markedly. The variance ratios for the entire period and for the period since October 1990 provide no indication of a thin-market effect. The decline of the variance ratios is nearly monotonic, as one would expect if there were an important risk premium. The curve for the entire sample lies above that for the period ending in 1998, because after short-term rates achieved the zero bound, long-term rates became much more variable than short-term rates.

The variance ratios for the first-difference data also give no indication of a significant thin-market 


\section{Figure 3}

\section{Ratio of the Variance of Each Rate to the Variance of R3 for Selected Periods}

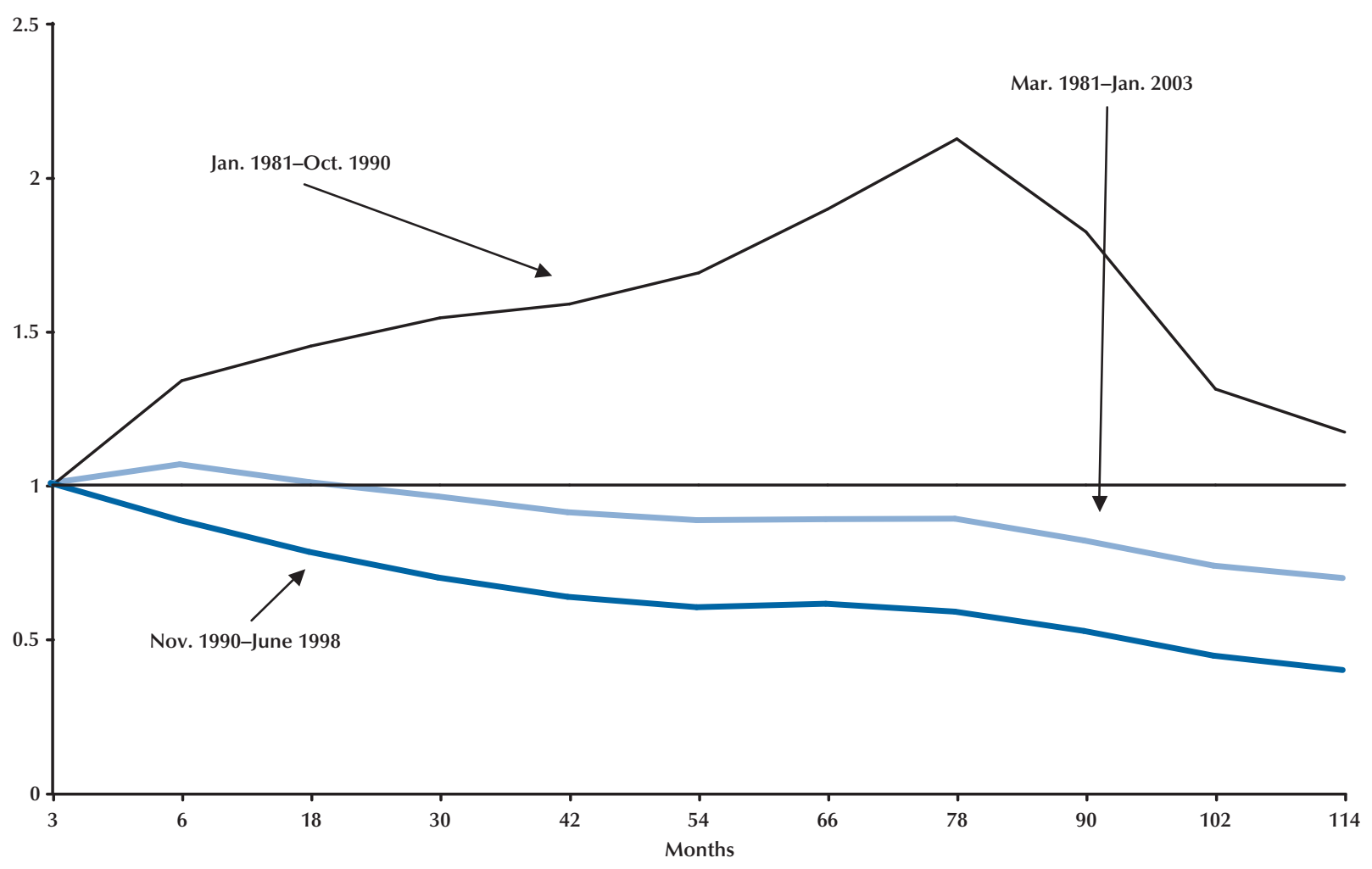

effect. While the variance ratio first rises and then declines during the November 1990-June 1998 period, the sharp decline in the variance occurs before the maturity approaches 10 years. This simple analysis suggests that the thinness of the market may not be important for this research. If it is, it would appear to be important only for the level of rates and for the period March 1981-October 1990.

\section{IMPLICATIONS OF}

\section{NONSTATIONARITY FOR THE EH}

\section{A. Nonstationarity}

Given the evidence of nonstationarity in Japanese interest rates, it is important to ask, What, if anything, does nonstationarity imply for the $\mathrm{EH}$ ? To answer this question, assume that the stochastic process driving the short-term rate is

$$
r_{t}^{m}=\rho r_{t-1}^{m}+\varepsilon_{t},
$$

where $r_{t}^{m}$ is the current value of the short-term, $m$-period rate; $\rho$ is a parameter such that $0 \leq \rho \leq 1$; and $\varepsilon_{t}$ is an i.i.d. random variable distributed with a mean zero and a variance $\sigma^{2}$. If $0 \leq \rho<1$, the shortterm interest is generated by a stationary stochastic process. If $\rho=1$, on the other hand, the stochastic process is said to be I(1). In this case, stationarity is achieved by first-differencing the short-term rate.

The EH assumes that

$$
r_{t}^{n}=(1 / k) \sum_{i=0}^{k-1} E_{t} r_{t+m i}^{m}+\pi
$$

where $r_{t}^{n}$ is the long-term, $n$-period rate, and $k=n / m$ is an integer. If the short-term rate is a unit root process, $E_{t} r_{t+m i}^{m}=r_{t}^{m}$ for all $i$. Note that $E_{t} r_{t+m i}^{m}$ equals $r_{t}^{m}$ rather than $r_{t-1}^{m}$, because in the EH literature it is assumed that the short-term rate is observed when the long-term rate is determined. Substituting into the above expression and simplifying yields

$$
r_{t}^{n}=r_{t}^{m}+\pi \text {. }
$$

Therefore, if the short-term rate is I(1) and the EH holds, the long-term rate would always equal the 


\section{Figure 4}

\section{Ratio of the Variance of the First Difference of Each Rate to the Variance of the First Difference of $\mathbf{R 3}$ for Selected Periods}

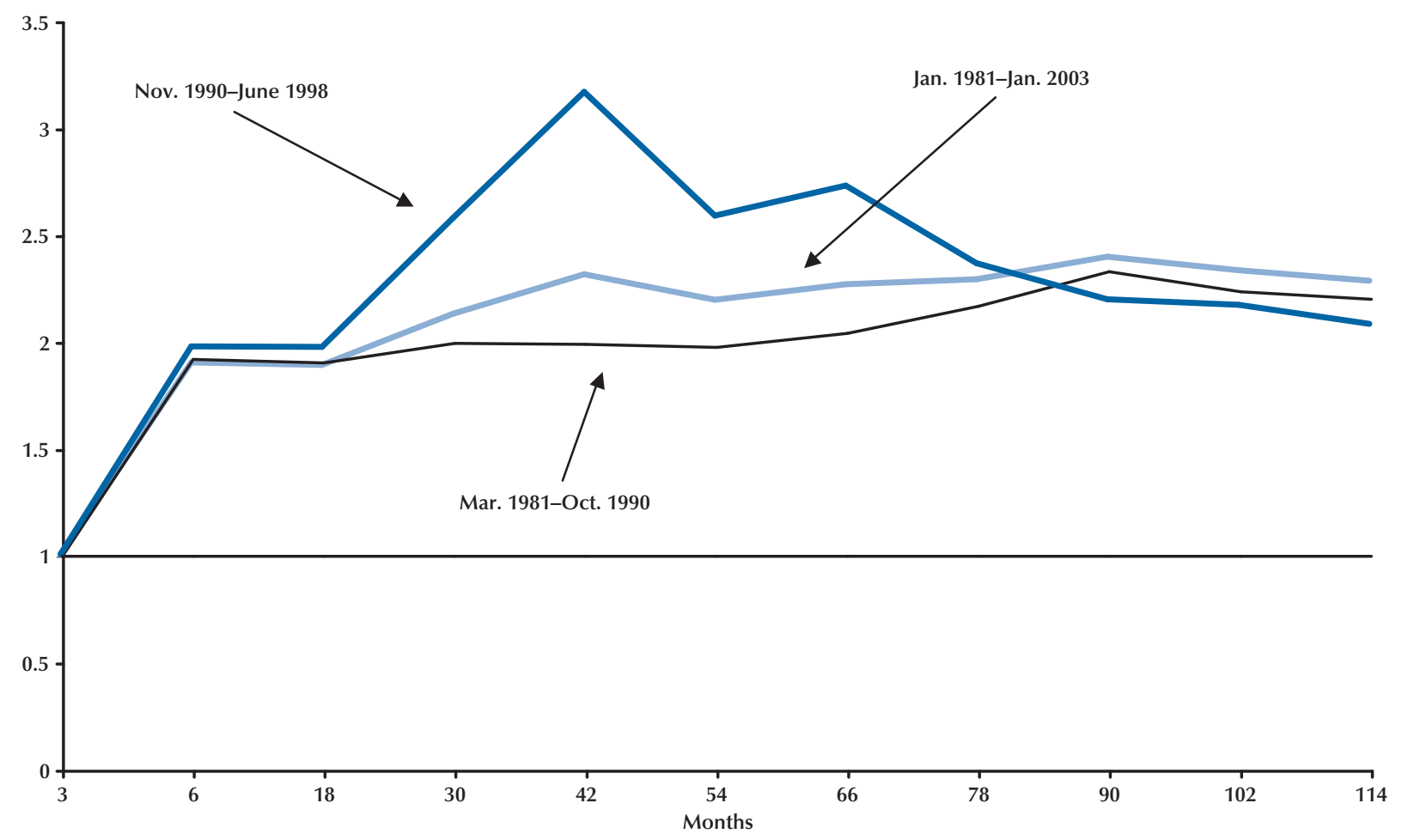

short-term rate plus a constant risk premium. This result stems from the fact that, if the short-term rate is I(1), the best estimate of the short-term rate at any horizon is its current level-changes in the short-term rate are unpredictable, i.e., $\Delta r_{t+i}^{m}=\varepsilon_{t+i}$ for all $i \geq 1.4$

The EH is useful to market participants and policymakers because, if it holds, the spread between the long-term rate and the short-term rate provides information about the future level of the short-term rate. If the short-term rate is impossible to predict, however, the spread between long-term and shortterm rates cannot provide useful information about the market's expectation for the short-term rate. In this case, the $\mathrm{EH}$ is of little practical use, even though (as in the example above) it holds.

4 If the short-term rate is not generated by a simple I(1) process (as in this example) but is nonstationary, the general idea still applies because the variance of the short-term rate is not finite. It would be the case, however, that there would be some predictability of changes in the short-term rate. Generally speaking, the degree of predictability will be positively related to the extent to which the root is greater than 1 .

\section{B. Cointegration}

The above analysis ignores the possibility that the short-term and long-term rates are cointegrated. If these rates are unit root processes, but cointegrated, they are stationary in levels in the direction of the cointegrating vector. The idea of cointegration is illustrated by assuming that the long-term and shortterm interest rates are jointly endogenous and that the true data-generating process can be approximated by a VAR of the form

$$
y_{t}=\Theta(L) y_{t-1}+\eta_{t},
$$

where $y_{t}=\left(r_{t}^{m}, r_{t}^{n}\right)$ and $\Theta(L)$ is a $P$-order polynomial in the lag operator $L$. Equation 4 can be written as

$$
\Delta y_{t}=\Psi(L) \Delta y_{t-1}-\Pi y_{t-1}+\eta_{t},
$$

where $\Pi=(I-\Theta(1))$. If $y_{t}$ is stationary, the rank of $\Pi$ is 2 . In this case, any linear combination of the longand short-term rates is stationary. If the short- and long-term rates have a unit root, however, the rank 
of $\Pi$ is at most 1 . If the rank of $\Pi$ is 1 , the long- and short-term rates are cointegrated. In this case, $\alpha \beta^{\prime}=\Pi$, where $\alpha$ and $\beta$ are $2 \times 1$ vectors. The cointegrating vector, $\beta$, represents the long-run equilibrium relationship between the long- and short-term interest rates, i.e., the direction in which the relationship between the levels of the rates is stationary. Specifically, $\beta^{\prime} y_{t}$ is stationary (mean reverting). Hence, cointegration indicates that there is a stable equilibrium relationship between the levels of the short- and long-term interest rates, but only in the direction of the cointegrating vector. When the variables are cointegrated, $\alpha \beta^{\prime} y_{t-1}$ replaces $\Pi y_{t-1}$ in (5) and the resulting equation is referred to as an errorcorrection model (ECM), where the coefficients in $\alpha$ measure the speed with which the rates adjust to their long-run equilibrium.

\section{Cointegration and the EH}

If the rates are nonstationary but cointegrated, one can test the EH by testing the hypothesis that the cointegrating vector (adjusted for the constant risk premium and/or a deterministic trend) equals $(1,-1)$. This test has been used by a number of researchers (e.g., Stock and Watson, 1988; Hall, Anderson, and Granger, 1992; Engsted and Tanggaard, 1994; and Sarno and Thornton, 2003).

Lack of cointegration is relatively strong evidence against the EH for two reasons. First, if the interest rates are truly I(1), rejecting the hypothesis of cointegration implies that there is no stable long-run relationship between the levels of the interest rates, that is, the EH cannot hold.

Second, it is well known that the power to reject the null hypothesis of nonstationarity is low when the root is close to 1 . Thus, it could be that interest rates are really I(0). If this is the case, however, it should not be too difficult to find evidence of cointegration, i.e., reject the null hypothesis that there is no stationary relationship between the long-term rate and the short-term rate. Therefore, failure to find evidence of at least one cointegrating relationship among stationary variables is relatively strong evidence against the $\mathrm{EH}$.

Finding cointegration, but rejecting the hypothesis that the cointegrating vector is $(1,-1)$, is also relatively strong evidence against the $\mathrm{EH}$ because it suggests that the equilibrium relationship is in a direction that is inconsistent with the $\mathrm{EH}$. If the $\mathrm{EH}$ does not hold in the long-run equilibrium, there is little reason to expect that it will hold at frequencies that are of interest to policymakers and financial analysts.

On the other hand, finding that the $\mathrm{EH}$ holds in the long run does not necessarily imply that the $\mathrm{EH}$ is useful for policymakers and market analysts. To be useful, longer-term rates must respond reasonably quickly to changes in the policy rate. Hence, failing to reject the hypothesis that the cointegrating vector is $(1,-1)$ does not establish that the EH holds at frequencies that are of interest to policymakers and financial market analysts. Policymakers and financial analysts need to know how quickly the long-term rate can be expected to adjust to policyinduced changes in the short-term rate.

\section{TESTING THE EH FOR JAPANESE TREASURY RATES}

If the $\mathrm{EH}$ holds, on average, the long-term rate will equal the short-term rate plus a constant risk premium. A simple way to test the $\mathrm{EH}$ is to test for a unit root in the spread between the long-term and short-term rates. ${ }^{5}$ Figure 5 presents spreads between 6-month and 114-month Treasury rates and the gensaki rate. Other spreads tend to lie within the boundaries established by these spreads. Both spreads exhibit considerable persistence, suggesting the possibility that the null hypothesis of nonstationarity will not be rejected.

Augmented Dickey-Fuller tests of all of the spreads, for the entire sample period and for the March 1981-October 1990 period, are presented in Table 2. As before, the lag lengths were chosen by the Schwarz criterion and are denoted in parentheses below the Dickey-Fuller test statistic. The unit root hypothesis is rejected for all rate spreads except the 114-month rate for the entire sample period and for some of the intermediate maturities for the period ending October 1990.

The temporal stability of this conclusion is investigated by a rolling simple Dickey-Fuller test for the rate spreads using a sample of 78 monthly observations. The results for R114, R54, and R6 are presented in Figure 6. R54 is shown because the test statistics for rates with maturities longer than 42 months were generally larger than those for the 42-month rate. The results suggest that the null hypothesis of a unit root is somewhat borderline for the spread between the 42-month Treasury rate

\footnotetext{
5 See Dickey, Jansen, and Thornton (1991, pp. 59-60) for a discussion of why this is appropriate.
} 


\section{Figure 5}

\section{Selected Rate Spreads}

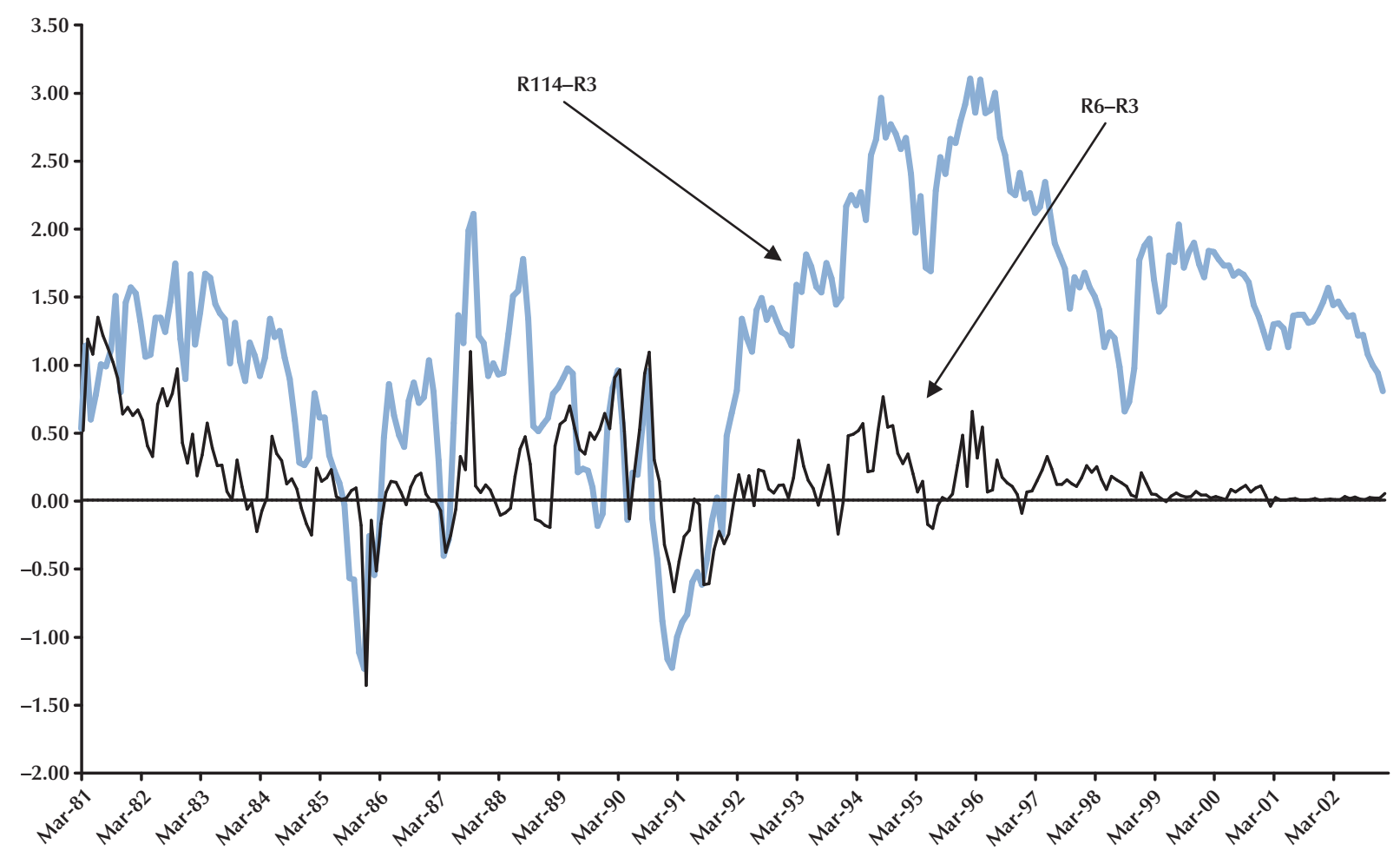

\section{Table 2}

Augmented Dickey-Fuller Tests of Japanese Treasury Rate Spreads

\begin{tabular}{|c|c|c|c|c|c|c|c|c|c|c|}
\hline Long rate & $\mathbf{R 6}$ & R18 & R30 & R42 & R54 & $\mathbf{R 6 6}$ & R78 & R90 & R102 & R114 \\
\hline \multicolumn{11}{|c|}{ March 1981-January 2003} \\
\hline DF & $\begin{array}{c}-5.50^{*} \\
(1)\end{array}$ & $\begin{array}{c}-4.94^{*} \\
(1)\end{array}$ & $\begin{array}{c}-4.47^{*} \\
(1)\end{array}$ & $\begin{array}{c}-4.07^{*} \\
(0)\end{array}$ & $\begin{array}{c}-3.48^{*} \\
(0)\end{array}$ & $\begin{array}{c}-3.15^{*} \\
(0)\end{array}$ & $\begin{array}{c}-3.15^{*} \\
(1)\end{array}$ & $\begin{array}{c}-3.40^{*} \\
(1)\end{array}$ & $\begin{array}{c}-2.95^{*} \\
(0)\end{array}$ & $\begin{array}{c}-2.79 \\
(0)\end{array}$ \\
\hline \multicolumn{11}{|c|}{ March 1981-October 1990} \\
\hline DF & $\begin{array}{c}-3.66^{*} \\
\text { (1) }\end{array}$ & $\begin{array}{c}-3.46^{*} \\
(1)\end{array}$ & $\begin{array}{c}-3.35^{*} \\
(0)\end{array}$ & $\begin{array}{c}-3.25^{*} \\
(0)\end{array}$ & $\begin{array}{c}-2.84 \\
(0)\end{array}$ & $\begin{array}{c}-2.47 \\
(0)\end{array}$ & $\begin{array}{c}-2.65 \\
(1)\end{array}$ & $\begin{array}{c}-3.51^{*} \\
(1)\end{array}$ & $\begin{array}{c}-3.42^{*} \\
(0)\end{array}$ & $\begin{array}{c}-3.17^{*} \\
(0)\end{array}$ \\
\hline
\end{tabular}

NOTE: Parentheses indicate lag length; ${ }^{*}$ indicates significance at the 5 percent level. 


\section{Figure 6}

\section{Rolling Dickey-Fuller Test for Selected Interest Rate Spreads}

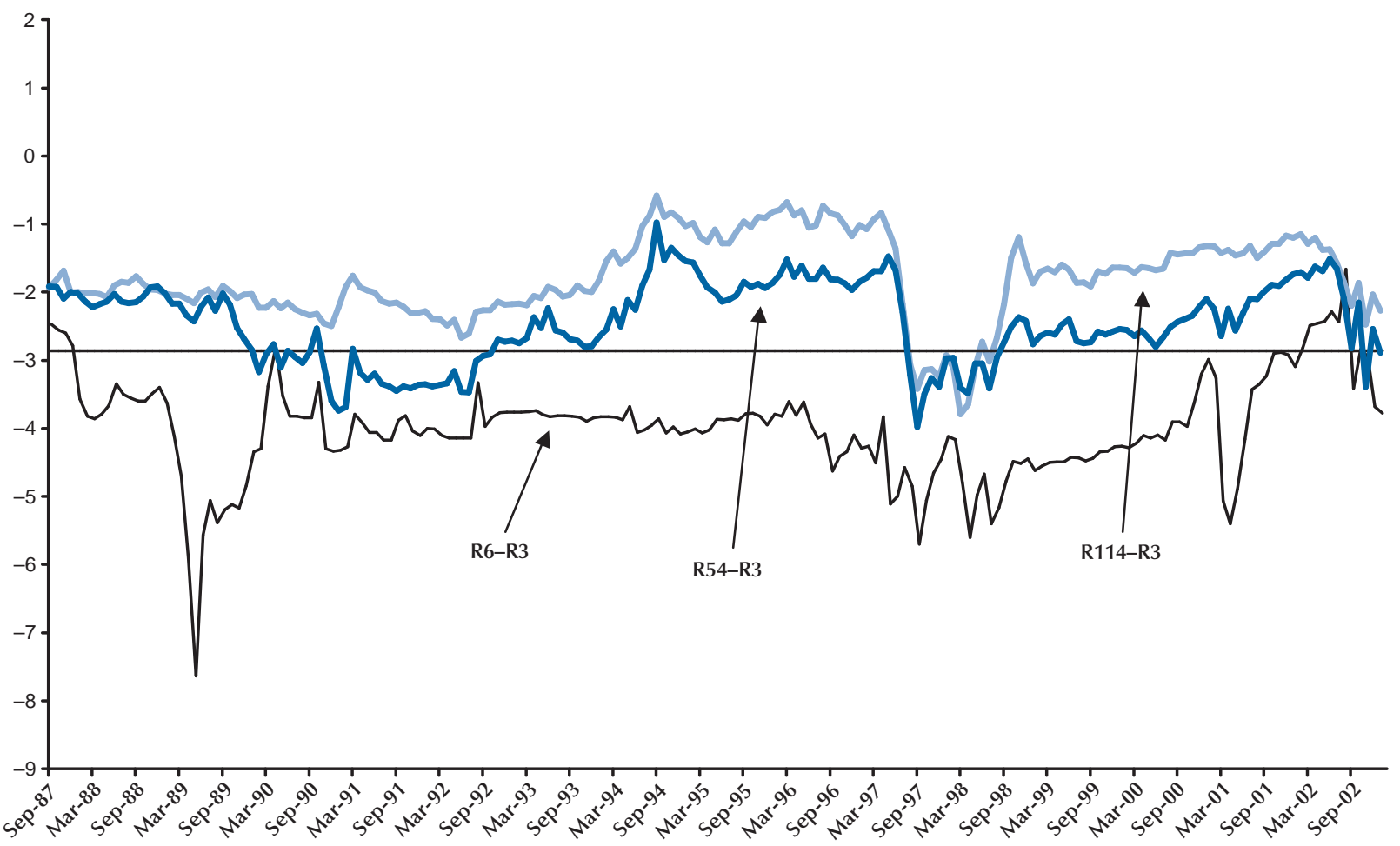

and the gensaki rate, but is infrequently rejected for Treasury rates with maturities longer than 42 months and frequently rejected for rates with maturities of less than 42 months. Furthermore, it appears that the null hypothesis is nearly always rejected when the long-term rate is 6 months. These results suggest that the EH may not hold when the long-term rate is 42 months or longer.

This conclusion is supported by formal tests for cointegration for three periods - the entire sample period, the period ending October 1990, and the period from November 1990-June 1998, before short-term rates reached the zero bound. ${ }^{6}$ The lag order and the precise form of the cointegration model are jointly determined by the Schwarz criterion. These results suggest that the 6-, 18-, 30-, and

6 Several alternative specifications of the cointegration model (allowing for a constant term and/or a deterministic trend in the cointegration relationship and no trend, a linear trend, or a quadratic trend in the structural dynamics) and alternative lag lengths from one through three were considered. The null hypothesis of at least one cointegrating vector is rejected in every case for the entire sample period and for the March 1981-October 1990 subperiod. 42-month rates are cointegrated with the 3 -month gensaki rate. The cointegration test results for rates with maturities of longer than 42 months indicate that these rates are not cointegrated with the gensaki rate for either the entire sample period or for the November 1990-June 1998 period. The results for the March 1981-October 1990 period are mixed. There are model specifications for which the null hypothesis of no cointegrating vector is rejected. These are not the specifications that minimized the Schwarz criterion, however. Moreover, when these models are estimated, the restriction that the cointegrating vector is $(1,-1)$ is easily rejected. For these reasons, the cointegration test results for maturities longer than 42 months are not presented.

Estimates of the cointegrating vectors for rates up to 42 months are presented in Table 3. The coefficient estimates are normalized on the shortterm rate, so Table 3 reports the estimate of the coefficient on the long-term rate and the $\chi^{2}$ test statistics for the null hypothesis that the cointegrating vector is $(1,-1)$. The estimated coefficients are close to -1 for the entire sample period and for the 


\section{Table 3}

\section{Estimated Cointegrating Vectors}

\begin{tabular}{lcccc} 
& R6 & R18 & R30 & R42 \\
\hline March 1981-January 2003 & & & & \\
Coefficient & -0.962 & -1.021 & -0.973 & -0.961 \\
& $(0.01)$ & $(0.02)$ & $(0.03)$ & $(0.05)$ \\
$\chi^{2}$ & 8.155 & 0.715 & 0.500 & 0.370 \\
& {$[0.004]$} & {$[0.399]$} & {$[0.479]$} & {$[0.543]$} \\
March 1981-October 1990 & & & & -0.952 \\
Coefficient & -0.96 & -0.957 & -0.960 & $(0.02)$ \\
& $(0.01)$ & $(0.02)$ & $(0.02)$ & 2.747 \\
$\chi^{2}$ & 6.077 & 4.079 & 2.426 & {$[0.097]$} \\
& {$[0.014]$} & {$[0.043]$} & {$[0.119]$} & -1.784 \\
November 1990-June 1998 & & & & $(0.19)$ \\
Coefficient & -1.171 & -1.308 & -1.488 & 14.903 \\
$\chi^{2}$ & $(0.04)$ & $(0.07)$ & $(0.12)$ & {$[0.000]$}
\end{tabular}

NOTE: Parentheses indicate standard errors; brackets indicate significance levels.

period March 1981-October 1990. The coefficient is more precisely estimated for the 6-and 18-month rates, so the null hypothesis that the cointegrating vector is $(1,-1)$ is rejected for the 6-month rate for the entire sample period and for both the 6- and 18-month rates for the period March 1981-October 1990. In these cases, however, the departure of the equilibrium relationship from that which is consistent with the EH is not large. At the shorter end of the maturity spectrum over the entire sample period and for the March 1981-October 1990 period, the equilibrium relationships appear to be more or less consistent with the $\mathrm{EH}$ holding in the long run.

The EH is easily rejected for the November 1990-June 1998 period, however. The point estimates of the coefficients on the long-term rate are very far from -1 . Moreover, the null hypothesis that the cointegrating vector is $(1,-1)$ is rejected for all rates at very low significance levels. Hence, as with previous empirical work, there is no evidence that long-term rates behave in a manner consistent with the EH during the more recent sample period.

\section{VAR TEST OF THE EH}

Campbell and Shiller (1987) suggest that the EH be tested by testing the restrictions imposed by the $\mathrm{EH}$ on a VAR of the short-term and long-term interest rates. The restrictions implied by the $\mathrm{EH}$ are highly nonlinear, however, and the Wald test, which they used, is known to be affected greatly by nonlinearity. Consequently, they suggested that the major advantage of their VAR approach came from its ability to generate economic measures of the relative importance of the EH.

Bekaert and Hodrick (2001) propose a method for testing the restrictions imposed on a VAR by the EH using a Lagrange multiplier (LM) test. Since this procedure is relatively new, it is outlined here in some detail. The test is illustrated using a VAR expressed in levels; however, only minor changes are required to use the Bekaert-Hodrick procedure to test Campbell and Shiller's (1987) specification.

\section{A. Bekaert and Hodrick Test}

This test is general and can be applied to any VAR specification where the restrictions implied by the EH can be imposed. To illustrate the procedure, it is assumed that interest rates are stationary, so that the VAR takes the form of (4), i.e.,

$$
(I-\Theta(L)) y_{t}=\eta_{t}
$$

for $y_{t}=\left(r_{t}^{m}, r_{t}^{n}\right)^{\prime}$. Generalized method of moments (GMM) estimation imposes orthogonality conditions 
of the form $g\left(z_{t}, \theta\right) \equiv \eta_{t} \otimes x_{t-1}$, where $x_{t-1}$ is a vector formed from stacking lagged values of $y_{t}$, possibly with a constant, $z_{t}$ is defined as $\left(y_{t}, x_{t-1}\right)^{\prime}$, and $\theta$ is a vector formed from the parameters in $\Theta(L)$. Using the sample moment condition,

$$
g_{T}(\theta) \equiv \frac{1}{T} \sum_{t=1}^{T} g\left(Z_{t}, \theta\right)
$$

GMM estimation proceeds by choosing $\theta$ to minimize the following objective:

$$
J_{T}(\theta) \equiv g_{T}(\theta)^{\prime} W g_{T}(\theta) .
$$

The optimal weighting matrix, $W$, is a consistent estimator of the inverse of

$$
\Omega \equiv \sum_{k=-\infty}^{k=\infty} E\left[g\left(Z_{t}, \theta\right) g\left(Z_{t-k}, \theta\right)^{\prime}\right] .
$$

GMM is used to estimate restricted VARs by forming a Lagrangian from the usual GMM quadratic objective and a vector of parameter constraints. The Lagrangian is defined

$$
L(\theta, \gamma)=-\frac{1}{2} g_{T}(\theta)^{\prime} \Omega_{T}^{-1} g_{T}\left(\theta-a_{T}(\theta)^{\prime} \gamma,\right.
$$

where $\gamma$ is a vector of Lagrange multipliers and the constraints on $\theta$ have been represented by the vectorvalued function, $a_{T}(\theta)=0$. Here the matrix $\Omega_{T}$ is again a consistent estimate of the matrix $\Omega$ defined above. Denoting the Jacobian of $g_{T}(\theta)$ and $a_{T}(\theta)$ by $G_{T}$ and $A_{T}$, respectively, the first-order conditions for maximizing $\bar{\theta}$ and $\bar{\gamma}$ can be written as

$$
\left[\begin{array}{c}
-G_{T}{ }^{\prime} \Omega_{T}^{-1} \\
-\sqrt{ } T g_{T}(\bar{\theta})-A_{T}{ }^{\prime} \sqrt{ } T \bar{\gamma} \\
-\sqrt{\theta} a_{T}
\end{array}\right]=\left[\begin{array}{l}
0 \\
0
\end{array}\right] .
$$

The asymptotic distribution of the constrained estimator can be derived from these first-order conditions by expanding $g_{T}(\theta)$ and $a_{T}(\theta)$ in Taylor series around the true parameter value, $\theta_{0}$, and substituting these into the first-order conditions above. This yields a system of the form

$$
\left[\begin{array}{l}
0 \\
0
\end{array}\right]=\left[\begin{array}{c}
-G_{T}{ }^{\prime} \Omega_{T}^{-1} \sqrt{ } T g_{T}\left(\theta_{0}\right) \\
0
\end{array}\right]-\left[\begin{array}{cc}
B_{T} & A_{T}{ }^{\prime} \\
A_{T} & 0
\end{array}\right]\left[\begin{array}{c}
\sqrt{ } T\left(\bar{\theta}-\theta_{0}\right) \\
\sqrt{ } T \bar{\gamma}
\end{array}\right],
$$

for $B_{T} \equiv G_{T}{ }^{\prime} \Omega_{T}^{-1} G_{T}$. Use of the partitioned inverse formula allows one to argue that the constrained estimator, $\bar{\theta}$, is distributed as $\sqrt{T}\left(\bar{\theta}-\theta_{0}\right) \rightarrow N\left(0, \Sigma_{T}\right)$ for

$$
\Sigma_{T} \equiv B_{T}^{-1}-B_{T}^{-1} A_{T}{ }^{\prime}\left(A_{T} B_{T}^{-1} A_{T}{ }^{\prime}\right)^{-1} A_{T} B_{T}^{-1}
$$

and the Lagrange multipliers are distributed asymptotically as

$$
\sqrt{ } T \bar{\gamma} \rightarrow N\left(0,\left(A_{T} B_{T}^{-1} A_{T}^{\prime}\right)^{-1}\right) .
$$

If the constraints have a significant impact on parameter estimation, then the estimated Lagrange multipliers should be significantly different from zero. The asymptotic distributions given above can be used to show that a test that the multipliers are jointly zero can be based on the statistic

$$
T \bar{\gamma}^{\prime}\left(A_{T} B_{T}^{-1} A_{T}{ }^{\prime}\right) \bar{\gamma},
$$

which is asymptotically distributed as $\chi^{2}(l)$, where $l$ is the number of restrictions imposed.

Maximization of the Lagrangian above is often computationally troublesome, so Taylor series approximations to $a_{T}(\theta)$ and $g_{T}(\theta)$ can again be used to derive a constrained estimate with similar asymptotic properties. Instead of expanding around the true value, $\theta_{0}$, the current estimate of the true value, $\theta_{i}$, is used to form a better approximation, $\theta_{i+1}$. Since

$$
g_{T}\left(\theta_{i+1}\right) \approx g_{T}\left(\theta_{i}\right)+G_{T}\left(\theta_{i+1}-\theta_{i}\right)
$$

and

$$
a_{T}\left(\theta_{i+1}\right) \approx a_{T}\left(\theta_{i}\right)+A_{T}\left(\theta_{i+1}-\theta_{i}\right),
$$

we can substitute in the first-order conditions for maximization to derive the following iterative method:

$$
\left[\begin{array}{l}
0 \\
0
\end{array}\right]=\left[\begin{array}{c}
-G_{T}^{\prime} \Omega_{T}^{-1} \sqrt{ } T g_{T}\left(\theta_{i}\right) \\
-\sqrt{ } T a_{T}\left(\theta_{i}\right)
\end{array}\right]-\left[\begin{array}{cc}
B_{T} & A_{T}{ }^{\prime} \\
A_{T} & 0
\end{array}\right]\left[\begin{array}{c}
\sqrt{ } T\left(\theta_{i+1}-\theta_{i}\right) \\
\sqrt{ } T \gamma_{i+1}
\end{array}\right] .
$$

The unconstrained VAR parameter estimates are used for the initial conditions and the procedure iterates until the constraints are satisfied. The moment conditions for VAR estimation should be uncorrelated over time. Hence, $\Omega_{T}$ is estimated by

$$
\Omega_{T}=\frac{1}{T} \sum_{t=1}^{T} g\left(Z_{t}, \theta_{U}\right) g\left(Z_{t}, \theta_{U}\right)^{\prime},
$$

evaluating the moment conditions at the unconstrained VAR parameter estimates. 
The constraints that the EH imposes on a VAR can be seen by writing the VAR in first-order form, that is,

$$
\left(\begin{array}{c}
r_{t}^{m} \\
r_{t}^{n} \\
r_{t-1}^{m} \\
r_{t-1}^{n} \\
\vdots \\
r_{t-k}^{m} \\
r_{t-k}^{n}
\end{array}\right)=\left(\begin{array}{ccccc}
\theta_{1} & \theta_{2} & \cdots & & \theta_{r} \\
I & 0 & & 0 \\
0 & I & & \vdots \\
\vdots & & \ddots & & \\
0 & & & I & 0
\end{array}\right)\left(\begin{array}{c}
r_{t-1}^{m} \\
r_{t-1}^{n} \\
r_{t-2}^{m} \\
r_{t-2}^{n} \\
\vdots \\
r_{t-k-1}^{m} \\
r_{t-k-1}^{n}
\end{array}\right)+\left(\begin{array}{c}
\eta_{t} \\
0 \\
\vdots \\
0
\end{array}\right),
$$

or simply $x_{t}=\Theta x_{t-1}+v_{t}$. Note that $E_{t}\left(x_{t+k}\right)=\Theta^{k} x_{t}$, so that $E_{t}\left(r_{t+k}^{m}\right)=e_{1}^{\prime} \Theta^{k} x_{t}$ for $e_{1}=(1,0, \ldots, 0)^{\prime}$. Note, too, that $r_{t}^{n}=e_{2}{ }^{\prime} x_{t}$ for $e_{2}=(0,1,0, \ldots, 0)^{\prime}$. Consequently, for any two interest rates such that $k=n / m$ is an integer, the EH implies that

$$
r_{t}^{n}=\frac{1}{k} \sum_{i=0}^{k-1} E_{t}\left(r_{t+m i}^{m}\right)
$$

so that the EH can be expressed equivalently as

$$
e_{2}^{\prime} x_{t}=\frac{1}{k} \sum_{i=0}^{k-1} e_{1}^{\prime} \Theta^{m i} x_{t} \text {. }
$$

The constraints that satisfy the $\mathrm{EH}$ are given by

$$
a_{T}(\theta) \equiv e_{2}^{\prime}-\frac{1}{k} \sum_{i=0}^{k-1} e_{1}^{\prime} \Theta^{m i}=0 .
$$

No simple closed form exists for the Jacobian of these constraints. Consequently, they are calculated numerically for use in the iterative procedure described above.

\section{B. Campbell and Shiller Test and Cointegration}

Campbell and Shiller's (1987) specific proposal stems from a concern that interest rates are nonstationary. Their test is based on the fact that (2) can be rewritten as

$$
S_{t}=E_{t} \sum_{i=1}^{k-1}(1-i / k) \Delta^{m} r_{t+m i}^{m},
$$

where $S_{t}=\left(r_{t}^{n}-r_{t}^{m}\right)$ and $\Delta^{m}$ denotes the $m$-horizon change, i.e., $\Delta^{m} w_{t}=w_{t+m}-w_{t}$. Specifically, Campbell and Shiller propose estimating a VAR representation,

$$
x_{t}=A(L) x_{t-1}+\omega_{t},
$$

where $x_{t}=\left(\Delta r_{t}^{m}, S_{t}\right)^{\prime}$ and $A(L)$ is a $P$-order polynomial in the lag operator $L$, and testing the restrictions implied by equation 22 . Noting that (23) can be rewritten as

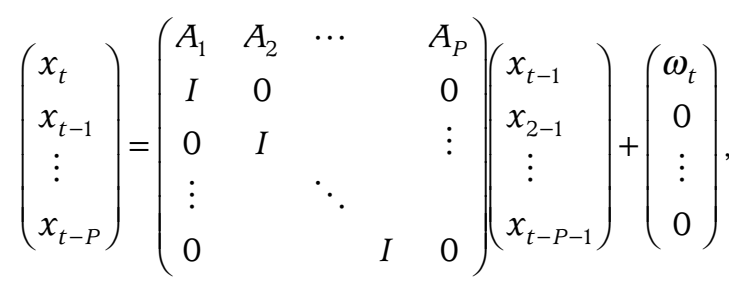

or more compactly as

$$
x_{t}^{*}=A x_{t-1}^{*}+\omega_{t},
$$

Campell and Shiller $(1987,1991)$ note that (22) can be written as

(26) $S_{t}=e_{1}^{\prime} A\left[I-(m / n)\left(I-A^{n}\right)\left(I-A^{m}\right)^{-1}\right](I-A)^{-1} x_{t}^{*}$.

Hence, the EH can be tested under the assumption that interest rates are nonstationary by testing the restriction

$$
e_{2}^{\prime}-e_{1}^{\prime} A\left[I-(m / n)\left(I-A^{n}\right)\left(I-A^{m}\right)^{-1}\right](I-A)^{-1}=0 .
$$

It should be noted that (4) and (23) are comparable $\left(\omega_{t}=\eta_{t}\right)$ if and only if the cointegrating vector is $(1,-1)$. In this case, Campbell and Shiller's test preserves the level relationship between the long-term and short-term rates because, under these conditions, (23) can be derived from simple algebraic manipulations of (4). ${ }^{7}$ Thus, in situations where the long-term and short-term rates satisfy the necessary conditions for the EH holding in the long run, Campbell and Shiller's specification provides a way of testing whether the EH holds at frequencies that are of interest to policymakers. ${ }^{8}$

\section{Results of VAR Tests}

The Bekaert-Hodrick procedure is applied to the VAR of the form of (4) under the assumption that interest rates are stationary. Because the LM test using the level specification is valid only if the VAR is stable, the maximum eigenvalue for each of the unrestricted VARs is calculated. In all instances, the maximum eigenvalue is less than 1 . The VAR test is also applied to the Campbell-Shiller VAR, (23), under the assumption that interest rates are non-

7 See Thornton (1985, especially the appendix) and Chow (1964) for a discussion of the role of normalization in regression analyses.

8 This test has been employed using a Wald test by Campbell and Shiller (1987) and Carriero, Favero, and Kaminska (2003) and using the LM test by Bekaert and Hodrick (2001) and Dittmar and Thornton (2003). 


\section{Table 4}

\section{LM Statistics for LM Test Using Level Data}

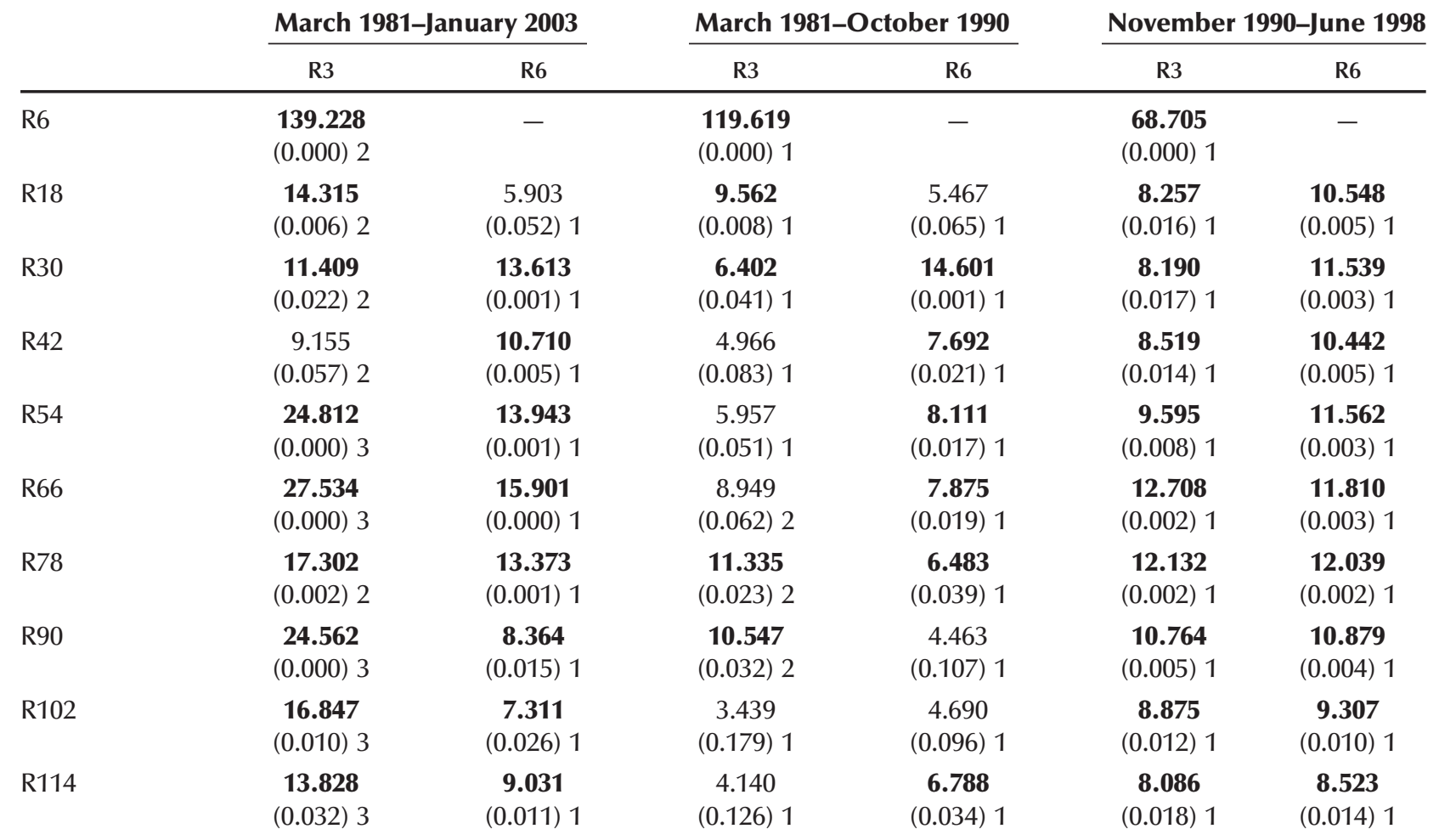

NOTE: Parentheses indicate significance levels; bold type indicates that the null hypothesis is rejected at the 5 percent significance level.

stationary. In all cases, following Bekaert and Hodrick (2001), the order of the VAR is determined by the Schwarz criterion.

Table 4 reports the LM statistic and the corresponding significance level for the tests on the VAR in levels. The lag length, chosen by the Schwarz criterion, is reported next to the significance level. Instances where the null hypothesis is rejected at the 5 percent level are in bold type. The results are reported using the 3-month gensaki rate and the 6month Treasury rate as the short-term rate. For the entire sample period, the restrictions implied by the $\mathrm{EH}$ are frequently rejected at the 5 percent significance level and in every case at a slightly higher significance level. This finding may reflect evidence that Japanese rates are nonstationary, particularly for rates at the longer end of the maturity spectrum, since it appears that such rates are not cointegrated with the gensaki rate.

The EH does not fare well either for the period ending on October 1990 or for the period November
1990-June 1998, where the EH is frequently rejected at the 5 percent significance level and nearly always at the 10 percent level. Instances where the $\mathrm{EH}$ is not rejected at the 5 percent level when the evidence indicates that the rates are not cointegrated suggests the possibility that the test has low power when rates are not cointegrated.

The LM test is also applied to the VAR suggested by Campbell and Shiller (1987). Recall that this test is valid only if the rates are cointegrated with a cointegrating vector of $(1,-1)$. Since interest rates are only cointegrated at the short end of the maturity spectrum and since the null hypothesis that the cointegrating vector is $(1,-1)$ is frequently rejected, this test may be valid only for short maturities and only then for the first two sample periods.

The results for this test for the three sample periods are presented in Table 5 . The results for the entire sample period are consistent with the results reported in Table 4 . With one exception (the 42month rate), the $\mathrm{EH}$ is rejected for the gensaki rate 


\section{Table 5}

\section{LM Statistics for Campbell-Shiller Test}

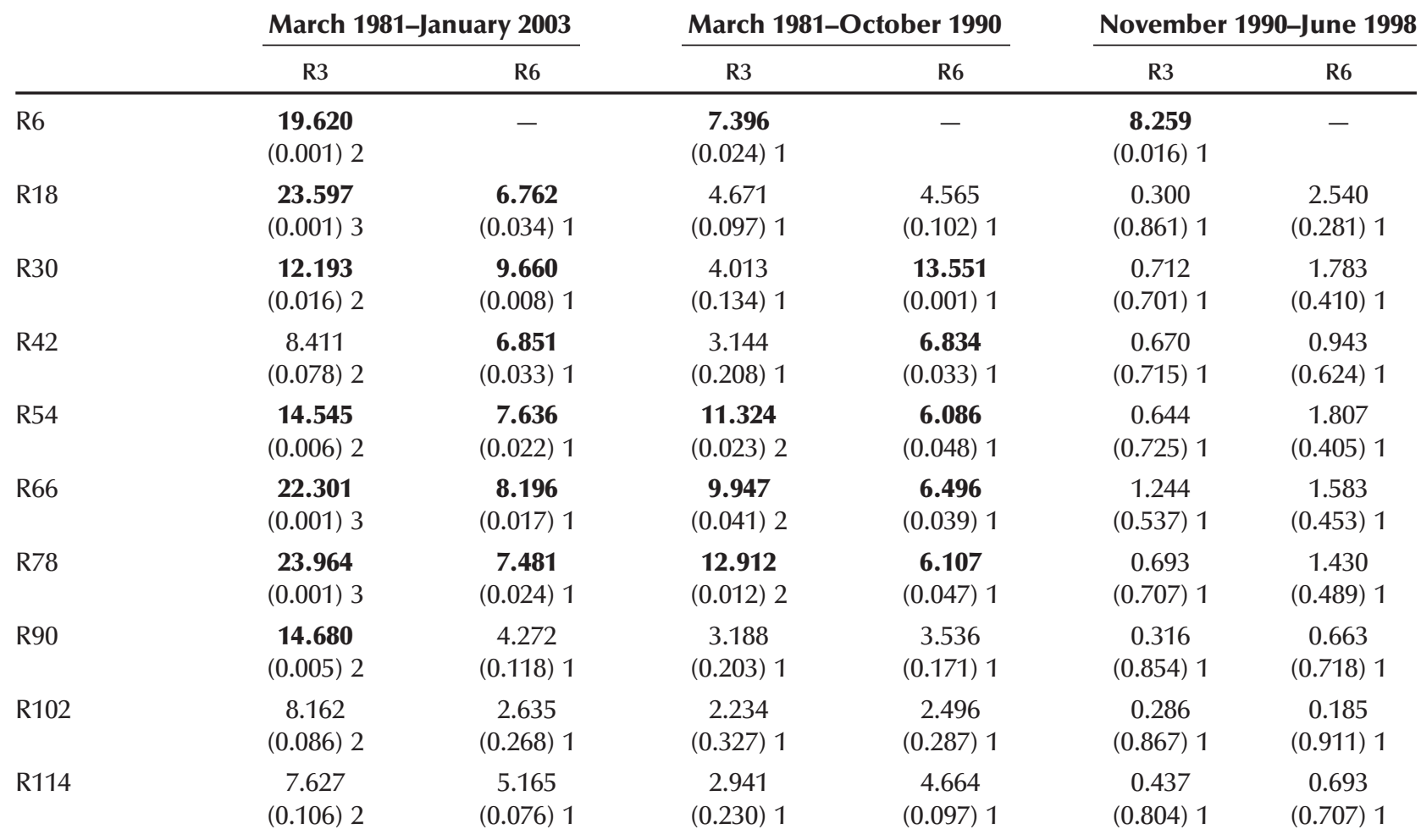

NOTE: Parentheses indicate significance levels; bold type indicates that the null hypothesis is rejected at the 5 percent significance level.

at a very low significance level for long-term rates shorter than 102 months. The failure of the test to reject the EH when the long-term rate is 42 months and longer than 90 months is surprising and may be indicative of low power when rates are not cointegrated or the cointegrating vector is not $(1,-1)$.

This interpretation is supported by the results for the March 1981-October 1990 and November 1990-June 1998 periods. When the gensaki rate is the short-term rate, the $\mathrm{EH}$ is rejected when the longterm rate is the 6-month rate. This is particularly true for the November 1990-June 1998 period, where the null hypothesis that the cointegrating vector is $(1,-1)$ is always rejected regardless of the maturity of the long-term rate and the restrictions implied by the $\mathrm{EH}$ are never rejected. In any event, that the test tends to fail to reject the EH when rates appear not to be cointegrated or when the cointegrating vector appears to be different from $(1,-1)$ suggests that this test may lack power when applied to data that do not satisfy the assumptions under which they are derived.

\section{IMPLICATIONS OF THE REJECTION OF THE EH FOR MONETARY POLICY}

Finding that the EH does not hold presents a problem for the conventional view of the monetary policy transmission processes. According to this view, the central bank controls a very short-term interest rate and the effects of monetary policy are transmitted to longer-term rates in accordance with the EH. Since it is widely believed that investment spending depends on the behavior of relatively longterm interest rates, the fact that the EH appears not to hold for longer-term rates is problematic for the conventional view of monetary policy.

It is important to note, however, that the extent of this problem depends on exactly why the EH does not hold. One explanation for the failure of the EHthe overreaction hypothesis (ORH) - does not necessarily reduce the effectiveness of policy. Indeed, the efficacy of policy could be enhanced. According to the $\mathrm{ORH}$, long-term rates overreact to expected 
changes in the short-term rate. Hence, during periods when the market expects interest rates to rise, longterm rates rise too much and too fast. Over time, and as expectations adjust, long-term rates fall while the short-term rate rises, which accounts for the failure of the EH. The ORH is not supported by evidence in the United States. Poole, Rasche, and Thornton (2002) show that the coefficient on a surprise change in the Federal Reserve Board's federal funds rate target for long-term rates is much smaller than that for short-term rates. Moreover, for rates longer than 12 months the estimated response is not statistically significant. Bekaert, Hodrick, and Marshall (2001) investigate a rational version of the $\mathrm{ORH}$ - namely, a "peso problem," where high interest rate regimes occur less frequently than rationally anticipated. They find that the peso problem cannot account for the failure of the $\mathrm{EH}$ in the United States.

Moreover, the ORH implies that long-term rates move more than short-term rates over the rate cycle. Thus, if the ORH is true, the variance of long-term rates should be generally larger than the variance of short-term rates. Figure 3 shows that this explanation is unlikely to account for the failure of the EH over the period January 1980-October 1990. The existence of the zero bound in the 1990s renders this explanation suspect since then.

Other explanations, such as the failure of rational expectations or, more generally, the market's inability to predict the behavior of interest rates, are more difficult for the conventional view of policy. ${ }^{9}$ Either explanation implies that long-term rates need not be determined solely or in large part by the market's expectation for the policy rate. In such a circumstance, it is hard to understand how policy actions that affect very short-term rates are predictably transmitted along the yield curve. Some recent work using U.S. interest rates (Diebold and $\mathrm{Li}$, 2003; Duffee, 2002; Carriero, Favero, and Kaminska, 2003; and Rudebusch, 2002) suggests that much of the failure of the EH in the United States might be due to the market participants' inability to forecast short-term rates.

One of the most frequently cited reasons for the failure of the $\mathrm{EH}$ is that the risk premium is time varying, rather than constant as the EH requires. One problem with this explanation is that any failure of the $\mathrm{EH}$ implies that the deviations in the risk premium are not i.i.d., i.e., they are not time invari-

\footnotetext{
9 For example, Balduzzi, Bertola, and Foresi (1997) attempt to reconcile some of the empirical results by arguing that they are due in part to the market's failure to predict policy-induced short-term rate changes.
}

ant. Hence, stating that the risk premium is time varying can be viewed as merely an alternative way of stating that the EH does not hold. For monetary policy to be effective, the actions of the monetary authority must be predictably transmitted to longerterm rates. For policy actions (which affect shortterm rates) to have their desired effect on long-term rates, policymakers must be able to predict how the risk premium will vary over time - the efficacy of policy depends on policymakers' ability to predict changes in the risk premium.

While it is important to know that the EH does not hold, it is equally important to understand why it does not hold. It is now well established that, generally speaking, the EH does not hold in Japan. Research should now be focused on investigating why.

\section{CONCLUSIONS}

The deregulation of the Japanese bond market has generated interest in testing the expectations hypothesis (EH) of the term structure using Japanese data. This paper extends that literature by testing the $\mathrm{EH}$ for Japanese Treasury rates ranging in maturity from 6 to 114 months. This paper differs from previous tests of the $\mathrm{EH}$ using Japanese data in that it (i) considers the effects of nonstationarity on the $\mathrm{EH}$, (ii) explicitly accounts for the stationarity of the data in testing the $\mathrm{EH}$, and (iii) tests the $\mathrm{EH}$ by testing the restrictions imposed by it on two different VAR specifications of the short-term and long-term rates: one that assumes that interest rates are stationary and another that assumes that interest rates are nonstationary.

The results under the assumption that interest rates are stationary are not supportive of the EH. The $\mathrm{EH}$ is nearly always rejected at the 5 percent significance level, and in all but two instances rejected at the 10 percent significance level over the entire sample period and the subperiods considered.

The results are somewhat more supportive of the EH if one assumes that interest rates are nonstationary. A necessary condition for the EH holding is that the short-term and long-term rates are cointegrated. The evidence indicates that the gensaki rate is cointegrated with Treasury rates, but only for rates with maturities of 42 months or shorter. Consequently, the evidence suggests that the $\mathrm{EH}$ is likely to hold only at the short end of the maturity spectrum. Even in some of these instances, however, the hypothesis that the spread between the long-term and short-term rates is the equilibrium cointegrat- 
ing vector is rejected. In these instances, the $\mathrm{EH}$ is rejected.

The Campbell and Shiller (1987) test is applied to all combinations of short- and long-term rates, despite the fact that most rates do not satisfy the necessary conditions for the test to be applied. The $\mathrm{EH}$ is nearly always rejected at the 5 percent significance level over the entire sample period. This is not the case for the two shorter samples, however. Indeed, for about half of the combinations of shortterm and long-term rates for the two shorter samples, the $\mathrm{EH}$ is not rejected, even at the 10 percent level. There are several issues that make this favorable interpretation for the EH problematic. First, and perhaps most troubling, the $\mathrm{EH}$ is rejected at a very low significance level when the short-term and longterm rates are the 3-month gensaki and 6-month Treasury rates, respectively. This is true for all three sample periods. Hence, the EH appears not to hold at the short end of the maturity spectrum, where most analysts (e.g., Rudebusch, 2002) believe that it is more likely to hold.

Second, the EH is frequently not rejected in cases where the evidence suggests (i) that interest rates are either not cointegrated or (ii) the spread between the long-term and short-term rates is not the cointegrating vector. Because the Campbell and Shiller (1987) test does not preserve the relationship between the levels of the rates if these conditions are not met, it is unclear whether the failure to reject the $\mathrm{EH}$ is because the $\mathrm{EH}$ holds or because the test has low power in such circumstances.

Third, relatively favorable results are obtained only when the gensaki rate is the short-term rate. When the 6-month rate is the short-term rate, the $\mathrm{EH}$ is frequently rejected at the shorter end of the term structure. Both this result and the rejection of the $\mathrm{EH}$ when the long-term rate is the 6-month rate could be due to idiosyncrasies in the behavior of the 6-month rate.

All in all, the EH appears not to fare well in Japan. If interest rates are nonstationary, the EH holds, at best, only at the short end of the maturity spectrum. This is encouraging, because most economists believe that the EH is likely to be the most relevant at the short end of the yield curve. This interpretation of the evidence presented here is consistent with recent analysis by Fujiki and Shiratsuka (2002) and Takeda and Yajima (2002), who find evidence that is broadly consistent with the EH using high-frequency, daily data over the period of the Bank of Japan's zero interest rate policy. Fujiki and Shiratsuka (2002) find that the yield curve flattens out over horizons of 3 months following the Bank of Japan's adoption of a zero interest rate policy and widens following the termination of the zero interest rate policy. ${ }^{10}$

\section{REFERENCES}

Balduzzi, Pierluigi; Bertola, Giuseppe and Foresi, Silverio. "A Model of Target Changes and the Term Structure of Interest Rates." Journal of Monetary Economics, July 1997, 39(2), pp. 223-49.

Bekaert, Geert and Hodrick, Robert J. "Expectations Hypotheses Tests.” Journal of Finance, August 2001, 56(4), pp. 1357-94.

Bekaert, Geert; Hodrick, Robert J. and Marshall, David A. “'Peso Problem' Explanations for Term Structure Anomalies." Journal of Monetary Economics, October 2001, 48(2), pp. 241-70.

Campbell, John Y. and Hamao, Yasushi. "The Interest Rate Process and the Term Structure of Interest Rates in Japan," in Kenneth J. Singleton, ed., Japanese Monetary Policy, NBER Monograph. Chicago: University of Chicago Press, 1993, pp. 95-120.

Campbell, John Y. and Shiller, Robert J. "Cointegration and Tests of Present Value Models." Journal of Political Economy, October 1987, 95(5), pp. 1062-88.

Campbell, John Y. and Shiller, Robert J. "Yield Spreads and Interest Rate Movements: A Bird's Eye View." Review of Economic Studies, May 1991, 58(3), pp. 495-514.

Carriero, Andrea; Favero, Carlo A. and Kaminska, Iryna. "Financial Factors, Macroeconomic Information and the Expectations Theory of the Term Structure of Interest Rates." Unpublished manuscript, 2003.

Chow, Gregory C. "A Comparison of Alternative Estimators for Simultaneous Equations.” Econometrica, October 1964, 32(4), pp. 532-53.

Dickey, David A. and Fuller, Wayne A. "Distribution of the Estimators for Autoregressive Time Series with a Unit Root." Journal of the American Statistical Association, June 1979, 74(366), pp. 423-31.

\footnotetext{
${ }^{10}$ Takeda and Yajima (2002) perform tests using longer-term interest rates and generate much less convincing evidence in support of the EH.
} 
Dickey, David A.; Jansen, Dennis W. and Thornton, Daniel L. "A Primer on Cointegration with an Application to Money and Income." Federal Reserve Bank of St. Louis Review, March/April 1991, 73(2), pp. 58-78.

Diebold, Francis X. and Li, Canlin. "Forecasting the Term Structure of Government Bond Yields.” NBER Working Paper No. 10048, National Bureau of Economic Research, October 2003.

Dittmar, Robert and Thornton, Daniel L. "Testing the Expectations Hypothesis: Some New Evidence.” Working Paper No. 2003-021B, Federal Reserve Bank of St. Louis, 2003.

Duffee, Gregory R. “Term Premia and Interest Rate Forecasts in Affine Models." Journal of Finance, February 2002, 57(1), pp. 405-43.

Engsted, Tom and Tanggaard, Carsten. "Cointegration in the U.S. Term Structure." Journal of Banking and Finance, January 1994, 18(1), pp. 167-81.

Fujiki, Hiroshi and Shiratsuka, Shigenori. "Policy Duration Effect under the Zero Interest Rate Policy in 1999-2000: Evidence from Japan's Money Market Data." Institute for Monetary and Economic Studies, Bank of Japan Monetary and Economic Studies, January 2002, 20(1), pp. 1-31.

Hall, Anthony D.; Anderson, Heather M. and Granger, Clive W.J. "A Cointegration Analysis of Treasury Bill Yields." Review of Economics and Statistics, February 1992, 74(1), pp. 116-26.

Higo, Hideaki. "The Change in Liquidity in the Life Cycle of Japanese Government Securities," in Market Liquidity: Research Findings and Selected Policy Implications, CGFS Publication No. 11, Bank for International Settlements, 2000 .

Hodder, James E. "The Cost of Capital for Industrial Firms in the U.S. and Japan," in William T. Ziemba, Waren Bailey, and Yasushi hamao, eds., Japanese Financial Market Research (Contributions to Economic Analysis, No. 205). Amsterdam: North-Holland, 1991, pp. 571-93.

Kool, Clemens J.M. and Thornton, Daniel L. "A Note on the Expectations Hypothesis at the Founding of the Fed." Working Paper No. 2000-004C, Federal Reserve Bank of St. Louis, 2003 (forthcoming in Journal of Banking and Finance).
Leung, Kwok-Wai; Sanders, Anthony and Unal, Haluk. "The Structural Behavior of the Japanese Gensaki Rate," in Japanese Financial Market Research (Contributions to Economic Analysis, No. 205). Amsterdam: North-Holland, 1991, pp. 557-68.

Okina, Kunio and Shiratsuka, Shigenori. "Policy Commitment and Expectation Formations: Japan's Experience under Zero Interest Rates.” IMES Discussion Paper No. 2003-E-5, Institute for Monetary and Economic Studies, Bank of Japan, 2003.

Poole, William; Rasche, Robert H. and Thornton, Daniel L. "Market Anticipations of Monetary Policy Actions." Federal Reserve Bank of St. Louis Review, July/August 2002, 84(4), pp. 65-93.

Rudebusch, Glenn D. “Term Structure Evidence on Interest Rate Smoothing and Monetary Policy Inertia." Journal of Monetary Economics, September 2002, 49(6), pp. 1161-87.

Sarno, Lucio and Thornton, Daniel L. "The Dynamic Relationship between the Federal Funds Rate and the Treasury Bill Rate: An Empirical Investigation." Journal of Banking and Finance, June 2003, 27(6), pp. 1079-110.

Shikano, Yoshiaki. "The Expectations Theory of the Term Structure of Interest Rates." Institute for Monetary and Economic Studies, Bank of Japan Monetary and Economic Studies, May 1985, 3(1), pp. 47-70.

Shirakawa, Hiromichi. "Fluctuations in Yields on BondsA Reassessment of the Expectations Theory Based on Japanese and U.S. Data." Institute for Monetary and Economic Studies, Bank of Japan, Monetary and Economic Studies, September 1987, 5(2), pp. 71-117.

Singleton, Kenneth J. "Interpreting Changes in the Volatility of Yields on Japanese Long-Term Bonds.” Institute for Monetary and Economic Studies, Bank of Japan Monetary and Economic Studies, January 1990, 8(1), pp. 49-77 (reprinted in Japanese Financial Market Research, 1991, pp. 527-56).

Stock, James H. and Watson, Mark W. "Testing for Common Trends." Journal of the American Statistical Association, December 1988, 83(404), pp. 1097-107.

Takagi, Shinji. "Recent Developments in Japan's Bond and Money Markets." Journal of the Japanese and International Economies, 1988, 2(1), pp. 63-91. 
Takeda, Yosuke and Yajima, Yasuhide. "How the Japanese Government Bond Market Has Responded to the Zero Interest Rate Policy.” NLI Research, February 2002.

Thornton, Daniel L. "Money Demand Dynamics: Some New Evidence.” Federal Reserve Bank of St. Louis Review, March 1985, 67(3), pp. 14-23.

Thornton, Daniel L. "The Conventional Test of the Expectations Hypothesis: Resolving the Anomalies When the Short-Term Rate Is the Federal Funds Rate." Working Paper 2000-003C, Federal Reserve Bank of St. Louis, 2002.

Thornton, Daniel L. "Tests of the Expectations Hypothesis: Resolving the Campbell-Shiller Paradox." Working Paper 2003-022b, Federal Reserve Bank of St. Louis, 2003a.

Thornton, Daniel L. "Monetary Policy Transparency: Transparent about What?" Manchester School, September, 2003b, 71(5), pp. 478-97. 
RE V I E W 